\title{
State of Charge Estimation for Lithium-Ion Batteries Based on Temperature-Dependent Second-Order RC Model
}

\author{
Yidan $\mathrm{Xu}^{1}$, Minghui $\mathrm{Hu}{ }^{1, *}$, Chunyun Fu ${ }^{1, * \mathbb{D}}$, Kaibin Cao ${ }^{1}$, Zhong Su ${ }^{2}$ and Zhong Yang ${ }^{2}$ \\ 1 State Key Laboratory of Mechanical Transmissions, School of Automotive Engineering, \\ Chongqing University, Chongqing 400044, China \\ 2 Chongqing Changan Automobile Co., Ltd., Chongqing 400023, China \\ * Correspondence: hu_ming@cqu.edu.cn (M.H.); fuchunyun@cqu.edu.cn (C.F.)
}

Received: 19 August 2019; Accepted: 7 September 2019; Published: 10 September 2019

\begin{abstract}
Accurate estimation of battery state of charge (SOC) is of great significance for extending battery life, improving battery utilization, and ensuring battery safety. Aiming to improve the accuracy of SOC estimation, in this paper, a temperature-dependent second-order RC equivalent circuit model is established for lithium-ion batteries, based on the battery electrical characteristics at different ambient temperatures. Then, a dual Kalman filter algorithm is proposed to estimate the battery SOC, using the proposed equivalent circuit model. The SOC estimation results are compared with the SOC value obtained from experiments, and the estimation errors under different temperature conditions are found to be within $\pm 0.4 \%$. These results prove that the proposed SOC estimation algorithm, based on a temperature-dependent second-order RC equivalent circuit model, provides accurate SOC estimation performance with high temperature adaptability and robustness.
\end{abstract}

Keywords: lithium-ion battery; temperature-dependent second-order RC model; SOC estimation; dual Kalman filter

\section{Introduction}

One fundamental challenge in the commercialization of electric vehicles is the battery system, and a safe and efficient battery system hinges on a reliable battery management system (BMS) [1]. At present, one of the main difficulties that hinder the development of BMS technology is the accurate estimation of state of charge (SOC). It has been pointed out that accurate SOC information is conducive to protecting batteries, preventing overcharging and over-discharging, improving battery utilization, and increasing the cruising range of electric vehicles [2-4].

However, the SOC cannot be directly monitored because of the battery systems' nonlinearity, time-varying characteristics, and the complexity of electrochemical reactions [5]. To tackle this problem, plenty of SOC estimation methods have been proposed in the literature. The existing SOC estimation methods can be divided into two major categories: non-model-based methods and model-based methods. The non-model-based methods mainly include the following: ampere hour (Ah) integration method [6], open circuit voltage (OCV) method [7], internal resistance method [8], and machine learning algorithms [9]. The model-based methods mainly include the following: particle filter (PF) [10], Kalman filter (KF) [11], and its improved algorithms [12-14].

Among the non-model-based methods, the Ah integration method is the simplest and most commonly used. Its implementation is straightforward and its computation load is low [15]. However, as an open-loop algorithm, the existence of uncertainties, such as noise, temperature, and current variations, can lead to large errors. The OCV method and internal resistance method rely on the correlation between the battery SOC and its external static characteristic parameter (i.e., OCV or 
internal resistance), and employ a look-up table to determine the estimated SOC value. However, the measurement of battery OCV requires even distribution of the electrolyte inside the battery. This process takes fairly long, which makes real-time measurement of OCV impossible [16]. Similarly, real-time measurement of battery internal resistance is also very difficult. As a result, neither the OCV method nor the internal resistance method can be used independently in practical applications. Besides, the machine learning algorithms are devised based on various mechanisms such as artificial neural networks [17], fuzzy logic inference [18], and support vector regression (SVR) [19]. These algorithms require a large amount of training data to establish the nonlinear relationship between the input to the battery and the output from the battery $[20,21]$. The performance of these algorithms is highly dependent on the quantity and quality of the training data, which in turn restricts the applicability and accuracy of these methods.

The model-based methods are more practical in terms of SOC online estimation. These methods rely on a high-precision battery model and adopt a closed-loop structure to perform SOC estimation with an unknown initial SOC value. These methods iteratively correct the SOC estimation error, using the difference between the measured terminal voltage and the battery model output. The PF [22] can achieve good results with non-Gaussian white noise; however, it leads to higher computational load compared with the KF. The KF is widely used owing to its capability of finding the optimal solution of linear Gaussian systems. In the work of [23], the KF is employed in conjunction with the Ah integration method, which improves the SOC estimation accuracy for lithium-ion batteries. Various improved KF algorithms, such as extended Kalman filter (EKF) [11] and double extended Kalman filter [24], have been extensively studied in battery SOC estimation. In the work of [25], an EKF based on the second-order RC model is proposed to reduce the influence of noise during the measurement process.

The current literature mainly focuses on the introduction of SOC estimation methods and their advantages and disadvantages. The SOC estimation errors for the existing methods are normally investigated under some specific scenarios. Duong et al. [26] proposed a multiple adaptive forgetting factors recursive least-squares (MAFF-RLS) technique for LiFePO4 battery SOC estimation. The maximum SOC estimation error is found to be $2.8 \%$ in two standard driving cycles, Urban Dynamometer Driving Schedule (UDDS) and New European Driving Cycle (NEDC). Yang et al. [27] compared the performances of several algorithms (i.e., EKF, UKF, and PF) for cylindrical-type 18,650 (LiFePO4) battery SOC estimation under a combined dynamic loading profile, which is composed of the dynamic stress test, the federal urban driving schedule, and the US06. In most circumstances, the three algorithms provided satisfactory SOC estimation results, as well as small root mean square errors (RMSEs) (less than $4 \%$ ).

In order to further improve the accuracy of SOC estimation, in this paper, the electrical characteristics of lithium-ion batteries under different ambient temperatures are analyzed, and a temperature-dependent second-order RC model is established. Then, a dual Kalman filter (DKF) algorithm is proposed based on the established model, which synthesizes the Ah integration method, the KF algorithm, and the EKF algorithm. The accuracy and temperature adaptability of the proposed SOC estimation algorithm are verified through experiments. The proposed battery model and SOC estimation method have taken into consideration the important effects of ambient temperature, and the results of this study can assist with the improvement of battery thermal management systems and enhance the reliability of electric vehicles operating in all climate conditions.

The rest of the paper is organized as follows. Section 2 describes the establishment of the temperature-dependent second-order RC model after analyzing the characteristics of lithium-ion batteries, Section 3 introduces the identification of unknown parameters involved in this model, Section 4 elaborates on the model verification process under different temperature conditions, Section 5 proposes a DKF algorithm for SOC estimation and its verification, and Section 6 concludes the paper. 


\section{Temperature-Dependent Second-Order RC Model}

The battery characteristics vary greatly at different temperatures. In order to improve the temperature adaptability of the battery model, temperature variation factors should be taken into account in the battery modeling process. In this section, the electrical characteristics of lithium-ion batteries at different ambient temperatures are firstly introduced. Then, a temperature-dependent second-order RC model is established, taking into account the effects of ambient temperature variations.

\subsection{Characteristics of Lithium-Ion Batteries}

When the current of the battery external circuit is zero and the internal electrochemical reactions are in equilibrium, the potential difference between the positive and negative electrodes is called the OCV [28]. The OCV is closely related to the battery SOC and the ambient temperature, and it is crucial for lithium-ion battery modeling and SOC estimation. As shown in Figure 1a, the OCV of the lithium-ion battery gradually decreases as the ambient temperature rises.

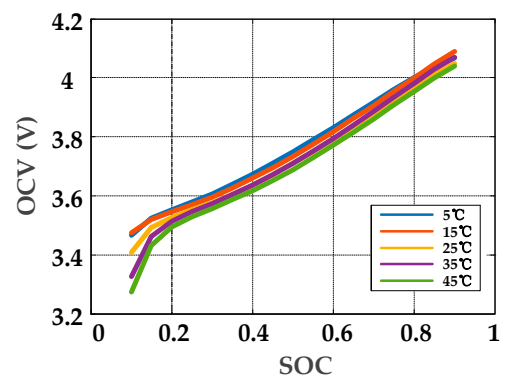

(a)

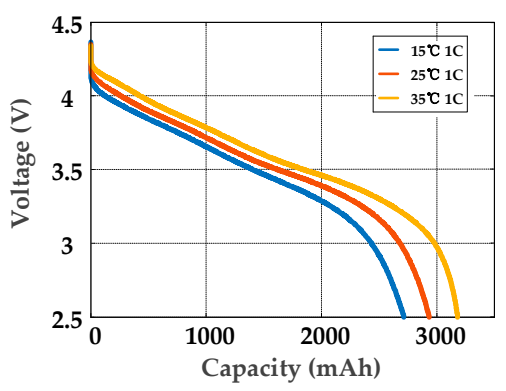

(b)

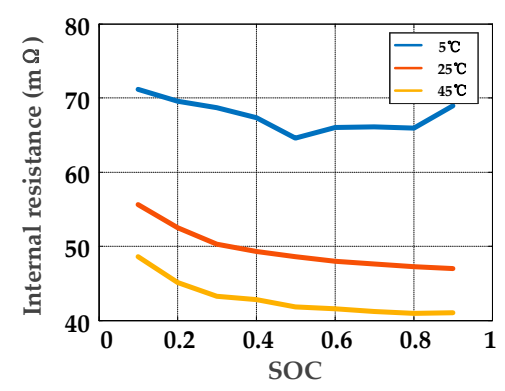

(c)

Figure 1. Battery characteristics under different ambient temperature conditions. (a) Relationship between state of charge (SOC) and open circuit voltage (OCV), (b) battery maximum discharge capacity, and (c) relationship between SOC and internal resistance.

With a certain discharge rate and a certain cutoff voltage, the amount of electricity that the battery can discharge is defined as the battery capacity [29]. The battery capacities at different ambient temperatures are shown in Figure $1 b$, where we see that the battery capacity increases as the ambient temperature increases.

Figure $1 \mathrm{c}$ shows how the battery internal resistance varies with the ambient temperature and SOC. We observe that the internal resistance decreases dramatically with the increase of ambient temperature; however, the influence of SOC on the internal resistance is insignificant.

\subsection{Battery Modeling}

On the basis of the influence of ambient temperature on lithium-ion batteries introduced in Section 2.1, a temperature-dependent second-order RC equivalent circuit model is established in this section, taking into account both model accuracy and model complexity. This model is composed of three modules: the OCV module, the internal resistance module, and the RC network module. The structure of the proposed model is shown in Figure 2, where $V_{\mathrm{t}}$ represents the battery terminal voltage, $V_{\text {ocv }}$ indicates the OCV, $V_{1}$ and $V_{2}$ denote the voltages generated by the polarization phenomenon, $I$ stands for the current (positive for charging and negative for discharging), $T$ represents the ambient temperature, $R_{0}$ is the ohmic internal resistance, $R_{1}$ and $R_{2}$ are the polarization internal resistances, and $C_{1}$ and $C_{2}$ are the polarization capacitances. It must be pointed out that the effects of SOC, temperature, and current direction changes on the above parameters have been taken into account in the battery modeling, as we will explain in Section 3. 


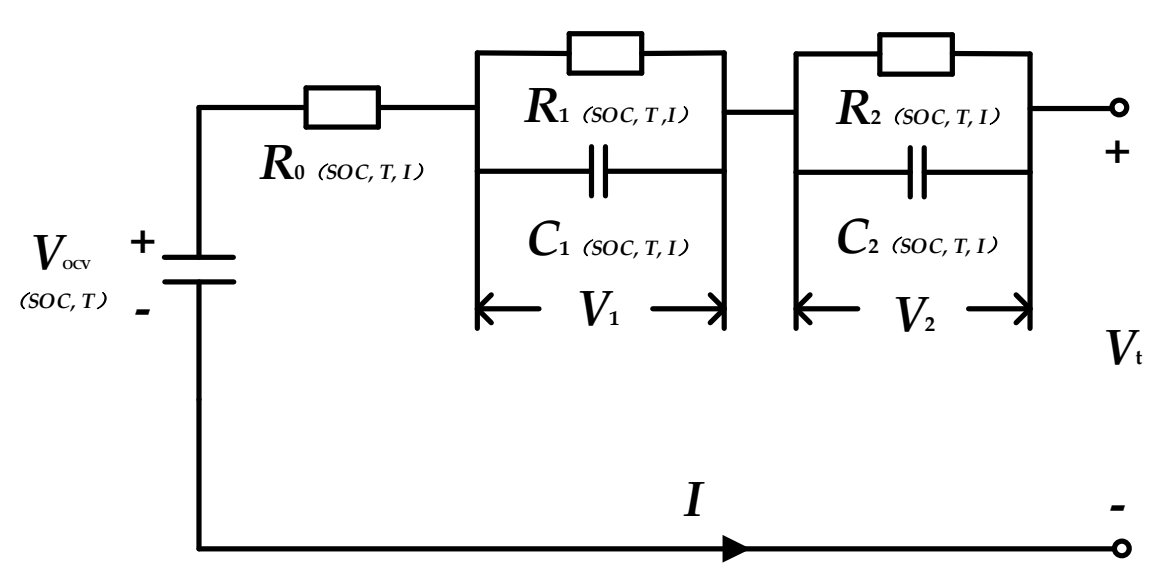

Figure 2. Structure of the proposed temperature-dependent second-order RC equivalent circuit model.

According to Kirchhoff's laws of voltage and current, the polarization voltages $V_{1}$ and $V_{2}$ satisfy the following rules:

$$
\begin{aligned}
& \dot{V}_{1}=-\frac{V_{1}}{R_{1} C_{1}}+\frac{I}{C_{1}}, \\
& \dot{V}_{2}=-\frac{V_{2}}{R_{2} C_{2}}+\frac{I}{C_{2}},
\end{aligned}
$$

where $\dot{V}_{1}$ and $\dot{V}_{2}$ denote the voltage change rates. The terminal voltage $V$ is given by the following:

$$
V=V_{\mathrm{OCV}}+R_{0} I+V_{1}+V_{2}
$$

The battery SOC is dependent on the available capacity and current direction, and it can be expressed as follows:

$$
\operatorname{SOC}(t)=\operatorname{SOC}\left(t_{0}\right)+\int_{t_{0}}^{t} \frac{\eta I(\tau)}{Q} d \tau
$$

where $\operatorname{SOC}(t)$ and $\operatorname{SOC}\left(t_{0}\right)$ are the SOC values at time $t$ and $t_{0}$, respectively; $\eta$ denotes the charging/discharging efficiency ( 0.98 for charging and 1 for discharging); and $Q$ represents the maximum available capacity. Assuming that the sampling time is $\Delta T$, discretizing Equations (1), (2) and (4) yields the following:

$$
\begin{gathered}
V_{1}(k)=\exp \left(\frac{-\Delta T}{R_{1} C_{1}}\right) V_{1}(k-1)+R_{1} I(k)\left[1-\exp \left(\frac{-\Delta T}{R_{1} C_{1}}\right)\right], \\
V_{2}(k)=\exp \left(\frac{-\Delta T}{R_{2} C_{2}}\right) V_{2}(k-1)+R_{2} I(k)\left[1-\exp \left(\frac{-\Delta T}{R_{2} C_{2}}\right)\right], \\
\quad S O C(k)=\operatorname{SOC}(k-1)+\frac{\eta t}{Q} I(k) .
\end{gathered}
$$

Equations (3) and (5)-(7) constitute the mathematical representation of the proposed temperature-dependent second-order RC model for lithium-ion batteries. These equations describe the dynamic characteristics of lithium-ion batteries at different temperatures, in a simple mathematical form with limited number of parameters.

Similar to our previous work [30], some parameters in this proposed battery model are not known a priori and need to be determined for model implementation. The parameters to be identified are $R_{1}$, $R_{2}, C_{1}, C_{2}, R_{0}, V_{\mathrm{OCV}}$, and $Q$. In the following section, we shall explain in detail how these unknown parameters can be identified. 


\section{Model Parameter Identification}

As mentioned above, the proposed battery model involves parameters that cannot be directly measured. Hence, in this section, we explain the detailed process for identifying these unknown parameters by means of experiments.

\subsection{Experiment Specifications}

The equipment used in our experimentation includes an incubator (HL404C, Well Test Equipment Co., Ltd., Chongqing, China), a battery testing device (BTS-5V100A, Neware Co., Ltd., Shenzhen, China), a set of measurement and control software, and a computer. In this study, a time interval of $0.1 \mathrm{~s}$ is used for data acquisition. The complete battery test system is shown in Figure 3. The Panasonic 18,650 ternary lithium-ion battery is used for testing, and its specifications are shown in Table 1.

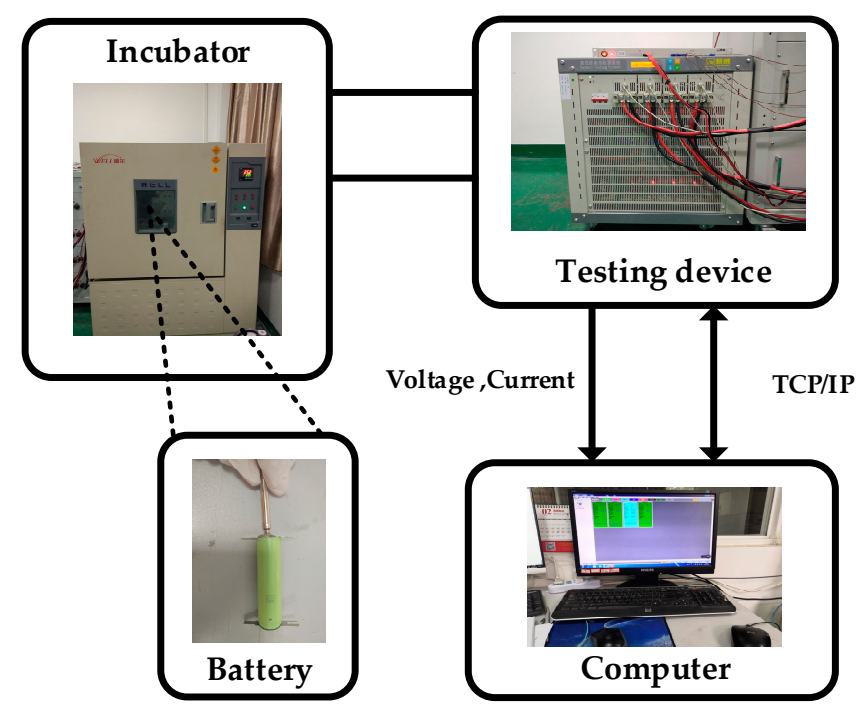

Figure 3. Battery test system.

Table 1. Specifications of the Panasonic 18,650 ternary lithium-ion battery.

\begin{tabular}{ccccc}
\hline Battery Model & Nominal Capacity & Rated Voltage & $\begin{array}{c}\text { Charge } \\
\text { Cutoff Voltage }\end{array}$ & $\begin{array}{c}\text { Discharge } \\
\text { Cutoff Voltage }\end{array}$ \\
\hline 18,650 & $3350 \mathrm{mAh}$ & $3.6 \mathrm{~V}$ & $4.2 \mathrm{~V}$ & $2.5 \mathrm{~V}$ \\
\hline
\end{tabular}

In order to identify the model parameters, the static capacity test (SCT), hybrid pulse power characteristic (HPPC) test, and double pulse discharge test were performed in this study, at five different ambient temperatures $\left(5^{\circ} \mathrm{C}, 15^{\circ} \mathrm{C}, 25^{\circ} \mathrm{C}, 35^{\circ} \mathrm{C}\right.$, and $\left.45^{\circ} \mathrm{C}\right)$, according to the work of [31]. The SCT was used for battery capacity $(Q)$ identification, and the double pulse discharge test was utilized to obtain the OCV $\left(V_{\mathrm{OCV}}\right)$ under specific SOC values. Parameters such as ohmic internal resistance $\left(R_{0}\right)$, polarization resistances $\left(R_{1}, R_{2}\right)$, and polarization capacitances $\left(C_{1}, C_{2}\right)$ were obtained by the HPPC test. The major test steps of the three tests are shown in Table 2. 
Table 2. Major test steps of the static capacity test (SCT), hybrid pulse power characteristic (HPPC), and double pulse tests.

\begin{tabular}{|c|c|c|}
\hline Test Name & & Test Steps \\
\hline \multirow{5}{*}{ SCT Test } & 1 & Battery shelved for $1 \mathrm{~h}$ \\
\hline & 2 & $0.2 \mathrm{C}$ constant current charging to charge cut-off voltage \\
\hline & 3 & Constant voltage charging to charge cut-off current \\
\hline & 4 & Battery shelved for $2 \mathrm{~h}$ \\
\hline & 5 & $0.2 \mathrm{C}$ constant current discharging to discharge cut-off voltage \\
\hline \multirow{6}{*}{ HPPC Test } & 1 & $1 \mathrm{C}$ constant current charging to charge cut-off voltage \\
\hline & 2 & Constant voltage charging to charge cut-off current \\
\hline & 3 & $1 \mathrm{C}$ constant current constant capacity ( $0.1 \mathrm{SOC})$ discharging \\
\hline & 4 & Battery shelved for $1 \mathrm{~h}$ \\
\hline & 5 & $\begin{array}{l}1 \mathrm{C} \text { constant current discharging for } 10 \mathrm{~s} \text {, battery shelved for } 40 \mathrm{~s}, 0.75 \mathrm{C} \\
\text { constant current charging for } 10 \mathrm{~s}\end{array}$ \\
\hline & 6 & $\begin{array}{l}\text { Repeat steps } 3 \sim 5 \text { to obtain battery internal resistances and power } \\
\text { characteristics at different SOC values }\end{array}$ \\
\hline \multirow{9}{*}{ Double Pulse Test } & 1 & $1 \mathrm{C}$ constant current discharging to discharge cut-off voltage \\
\hline & 2 & Battery shelved for $1 \mathrm{~h}$ \\
\hline & 3 & $0.5 \mathrm{C}$ constant current constant capacity ( $0.1 \mathrm{SOC}$ ) charging \\
\hline & 4 & Battery shelved for $2 \mathrm{~min}$ \\
\hline & 5 & Repeat steps 1 and 2 until the voltage reaches the charge cut-off voltage \\
\hline & 6 & Battery shelved for $12 \mathrm{~h}$ \\
\hline & 7 & $0.5 \mathrm{C}$ constant current constant capacity ( $0.1 \mathrm{SOC})$ discharging \\
\hline & 8 & Battery shelved for $2 \mathrm{~min}$ \\
\hline & 9 & Repeat steps 1 and 2 until the voltage reaches the discharge cut-off voltage \\
\hline
\end{tabular}

\subsection{Identification of $O C V$}

In practice, the battery OCV cannot be directly measured. However, there exists a certain correspondence between the OCV and SOC, which is crucial for OCV estimation. This relationship can be expressed by the following empirical equation [32]:

$$
V_{\mathrm{OCV}}=K_{1}+K_{2} S O C+K_{3} S O C^{2}+K_{4} S O C^{3}+K_{5} S O C^{4},
$$

where $K_{\mathrm{i}}(\mathrm{i}=1,2, \ldots 5)$ are five coefficients depending on the ambient temperature. The values of $K_{\mathrm{i}}$ determine the accuracy of the empirical Equation (8), and they can be obtained from the double pulse discharge test. The obtained coefficients of Equation (8) at different ambient temperatures are shown in Table 3, and the resulting 3D SOC-Temperature-OCV (SOC-T-OCV) map is shown in Figure 4. This SOC-T-OCV map is indeed a 3D look-up table, from which we can determine the OCV for certain values of $\mathrm{SOC}$ and ambient temperature.

Table 3. Coefficient values at different ambient temperatures.

\begin{tabular}{ccccc}
\hline Coefficient & $\mathbf{5}{ }^{\circ} \mathbf{C}$ & $\mathbf{1 5}{ }^{\circ} \mathbf{C}$ & $\mathbf{2 5}{ }^{\circ} \mathbf{C}$ & $\mathbf{3 5}{ }^{\circ} \mathbf{C}$ \\
\hline$K_{1}$ & 2.7758 & 2.81055 & 2.58785 & 2.4553 \\
$K_{2}$ & 1.6295 & 1.48735 & 1.78815 & 1.96495 \\
$K_{3}$ & -0.04675 & -0.04095 & -0.07095 & -0.1013 \\
$K_{4}$ & -0.43585 & -0.4026 & -0.5894 & -0.7354 \\
$K_{5}$ & 0.07365 & 0.02485 & 0.05735 & 0.05175 \\
\hline
\end{tabular}




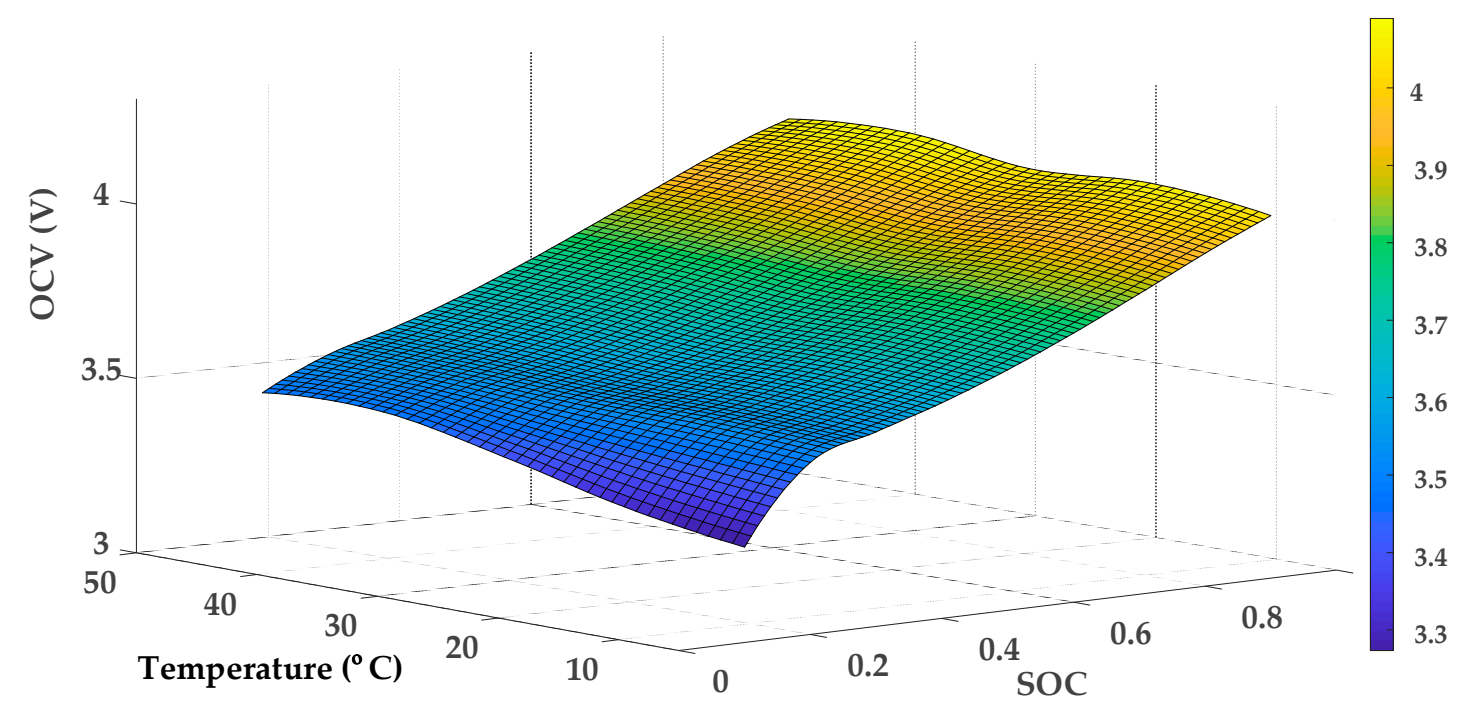

Figure 4. SOC-Temperature-OCV map.

\subsection{Identification of Internal Resistances and Capacitances}

In this section, we explain how to identify the internal resistances $\left(R_{0}, R_{1}\right.$, and $\left.R_{2}\right)$ and capacitances $\left(C_{1}\right.$ and $\left.C_{2}\right)$, by means of the HPPC test. In the HPPC test, the voltage and current vary according to the patterns shown in Figure 5. In this figure, one of the charge-discharge cycles is enlarged to clearly show the details.

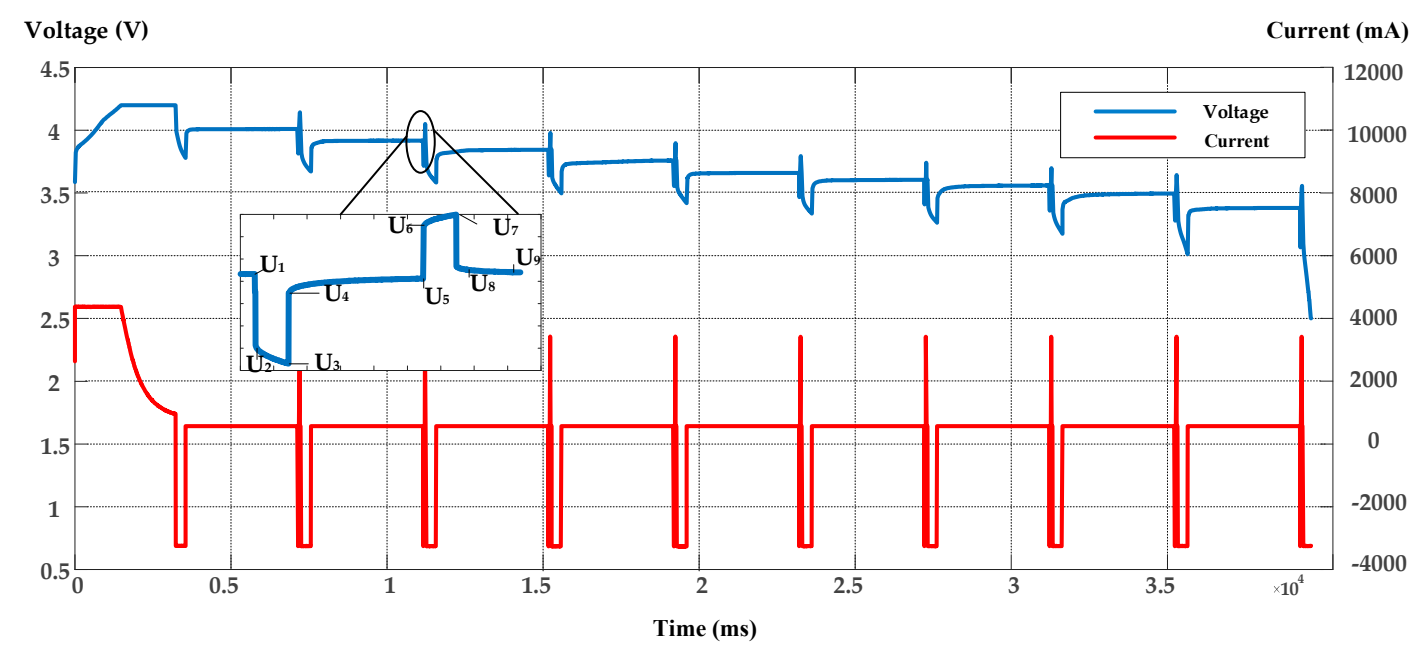

Figure 5. Voltage and current in the hybrid pulse power characteristic (HPPC) test.

Considering the discharge relaxation response curve $\left(\mathrm{U}_{4} \sim \mathrm{U}_{5}\right)$ and the charge relaxation response curve $\left(\mathrm{U}_{8} \sim \mathrm{U}_{9}\right)$ in Figure 5, the battery terminal voltage expression (i.e. Equation (3)) can be converted to the following equation, according to the work of [33]:

$$
V(t)=a+b \times \exp \left(-t / \tau_{1}\right)+c \times \exp \left(-t / \tau_{2}\right),
$$

where $a, b$, and $c$ are the fitting coefficients; and $\tau_{1}$ and $\tau_{2}$ are the time constants of the two RCs in Figure 2. The five coefficients $a, b, c, \tau_{1}$, and $\tau_{2}$ in Equation (9) can be obtained by means of curve fitting using MATLAB software.

Once the coefficients $a$ and $b$ are determined, the polarization internal resistances $R_{1}$ and $R_{2}$ can be calculated as follows:

$$
R_{1}=a / I
$$




$$
R_{2}=b / I,
$$

where $I$ is the measured current. The identification results for $R_{1}$ and $R_{2}$ are shown in Figure 6. It should be noted that the identification results for charging and discharging are different.

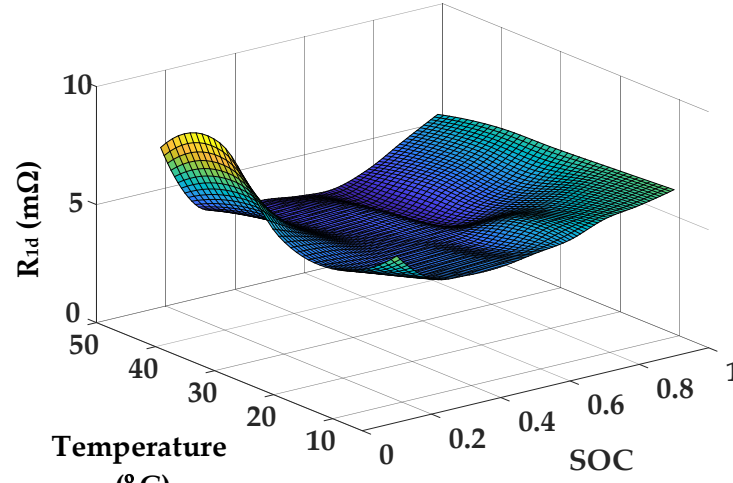

$\left({ }^{\circ} \mathrm{C}\right)$

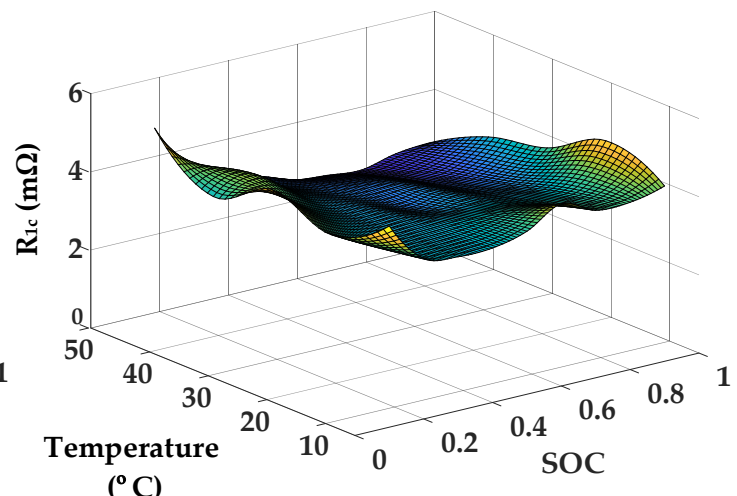

(b)

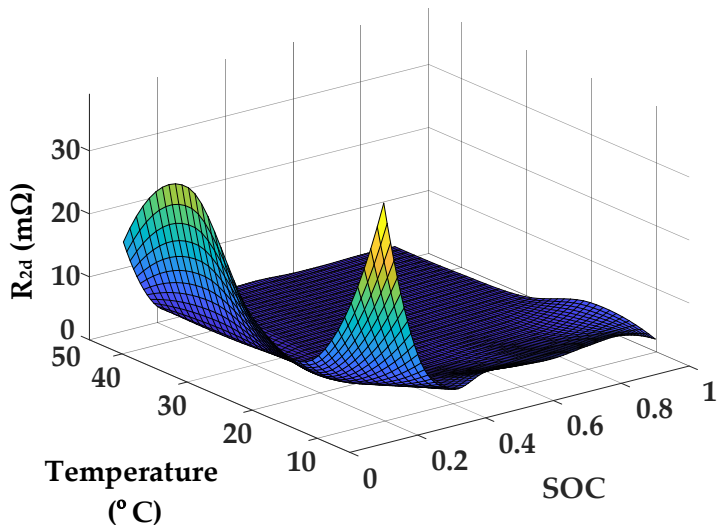

(c)

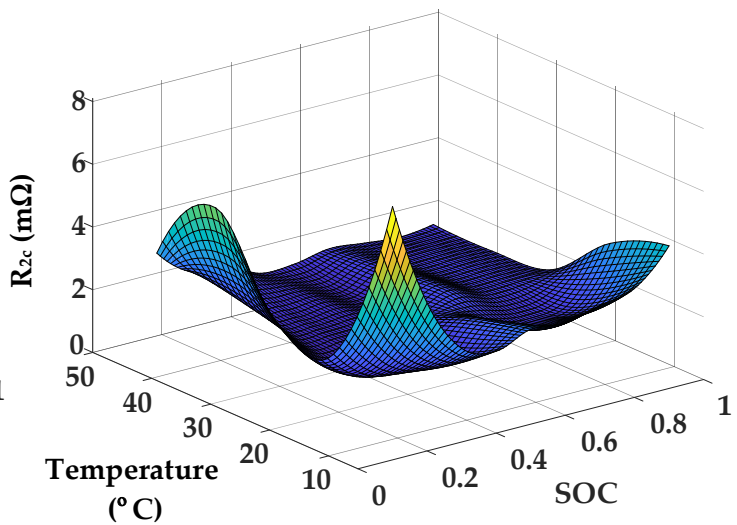

(d)

Figure 6. Polarization internal resistance identification results: (a) identified internal resistance for discharging, $R_{1 \mathrm{~d}} ;(\mathbf{b})$ identified internal resistance for charging, $R_{1 \mathrm{c}} ;(\mathbf{c})$ identified internal resistance for discharging, $R_{2 \mathrm{~d}}$; and (d) identified internal resistance for charging, $R_{2 \mathrm{c}}$.

After the internal resistances $R_{1}$ and $R_{2}$ are determined, the polarization capacitances $C_{1}$ and $C_{2}$ can be computed as follows:

$$
\begin{aligned}
& C_{1}=R_{1} / \tau_{1}, \\
& C_{2}=R_{2} / \tau_{2} .
\end{aligned}
$$

The identification results for $C_{1}$ and $C_{2}$ are shown in Figure 7. Similar to the case of polarization internal resistances, the capacitance identification results for charging and discharging are different. It is clearly seen in Figures 6 and 7 that the values of these four parameters, $R_{1}, R_{2}, C_{1}$, and $C_{2}$, are dependent on SOC, ambient temperature, and direction of current (i.e., charging or discharging). 


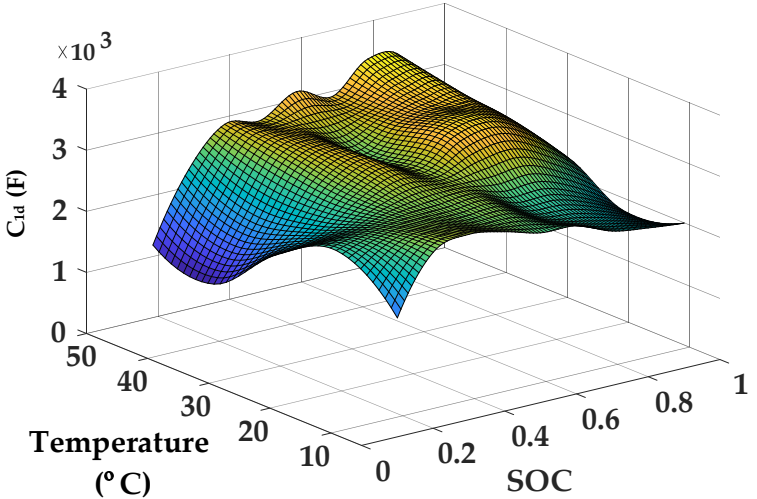

(a)

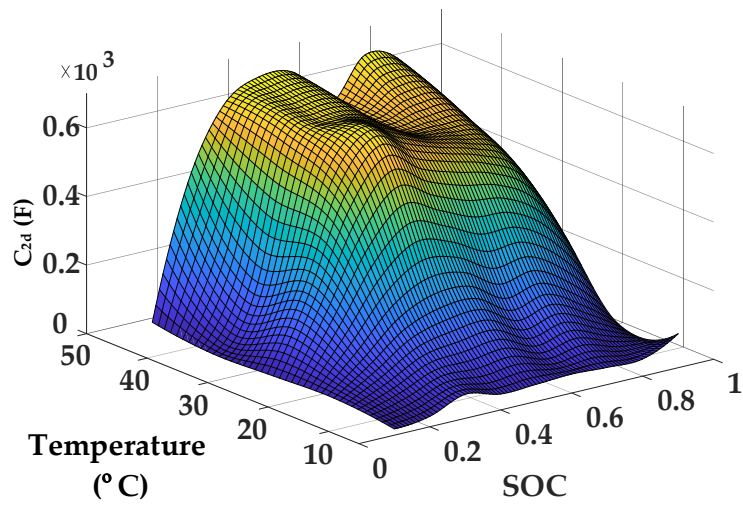

(c)

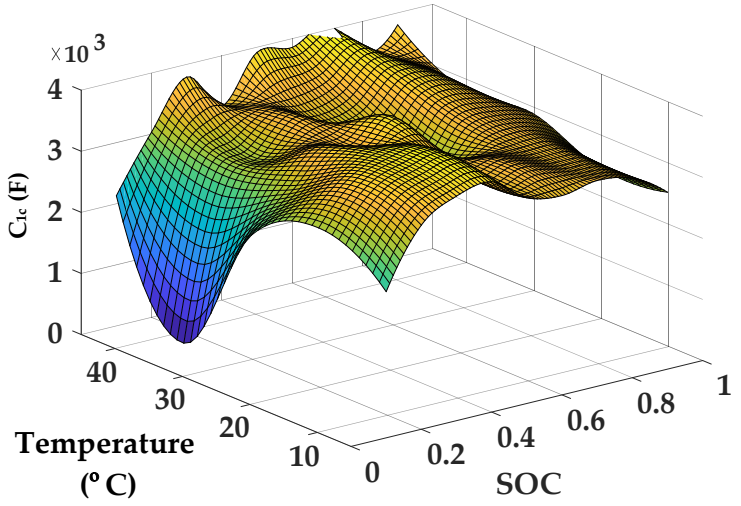

(b)

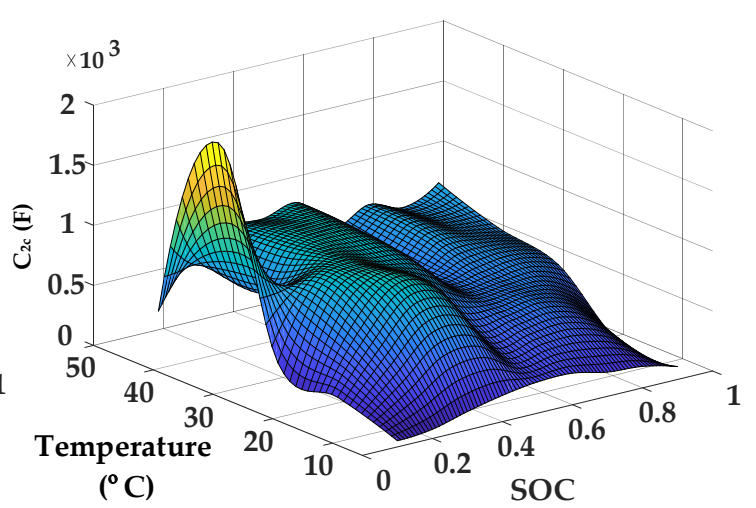

(d)

Figure 7. Polarization capacitance identification results: (a) identified capacitance for discharging, $C_{1 \mathrm{~d}} ;(\mathbf{b})$ identified capacitance for charging, $C_{1 \mathrm{c}} ;(\mathbf{c})$ identified capacitance for discharging, $C_{2 \mathrm{~d}} ;$ and (d) identified capacitance for charging, $C_{2 c}$.

Substituting the voltage drop values (as shown in Figure 5) in Equations (14) and (15), the ohmic internal resistance $R_{0}$ in the battery model is obtained:

$$
\begin{gathered}
R_{0 \mathrm{~d}}=\left(\left(U_{1}-U_{2}\right)+\left(U_{4}-U_{3}\right)\right) /\left(2 \times I_{\mathrm{d}}\right), \\
R_{0 \mathrm{c}}=\left(\left(U_{6}-U_{5}\right)+\left(U_{7}-U_{8}\right)\right) /\left(2 \times I_{\mathrm{c}}\right), \\
R_{0}=\left(R_{0 \mathrm{~d}}+R_{0 \mathrm{c}}\right) / 2 .
\end{gathered}
$$

where $R_{0 \mathrm{~d}}$ and $R_{0 \mathrm{c}}$ represent the ohmic internal resistances during discharging and charging, respectively; and $I_{\mathrm{d}}$ and $I_{\mathrm{c}}$ denote the discharging current and charging current, respectively. The identification results for the ohmic internal resistance $R_{0}$, at different ambient temperatures, are shown in Table 4 . It is seen that the value of $R_{0}$ drops as the ambient temperature increases.

Table 4. Identification results for the ohmic internal resistance, $R_{0}$.

\begin{tabular}{cccccc}
\hline Parameter & $\mathbf{5}^{\circ} \mathbf{C}$ & $\mathbf{1 5}{ }^{\circ} \mathbf{C}$ & $\mathbf{2 5}{ }^{\circ} \mathbf{C}$ & $\mathbf{3 5}{ }^{\circ} \mathbf{C}$ & $\mathbf{4 5}{ }^{\circ} \mathbf{C}$ \\
\hline$R_{0}$ & 0.067551 & 0.056435 & 0.048624 & 0.046138 & 0.043975 \\
\hline
\end{tabular}




\section{Model Verification and Discussion}

In this section, the accuracy of the proposed temperature-dependent second-order RC equivalent circuit model is verified. The schematic of the simulation model used for verification is shown in Figure 8. The identified parameters obtained from Section 3 are employed in the proposed model, and the model accuracy is evaluated in terms of the difference (error) between the measured terminal voltage and that resulting from the proposed model.

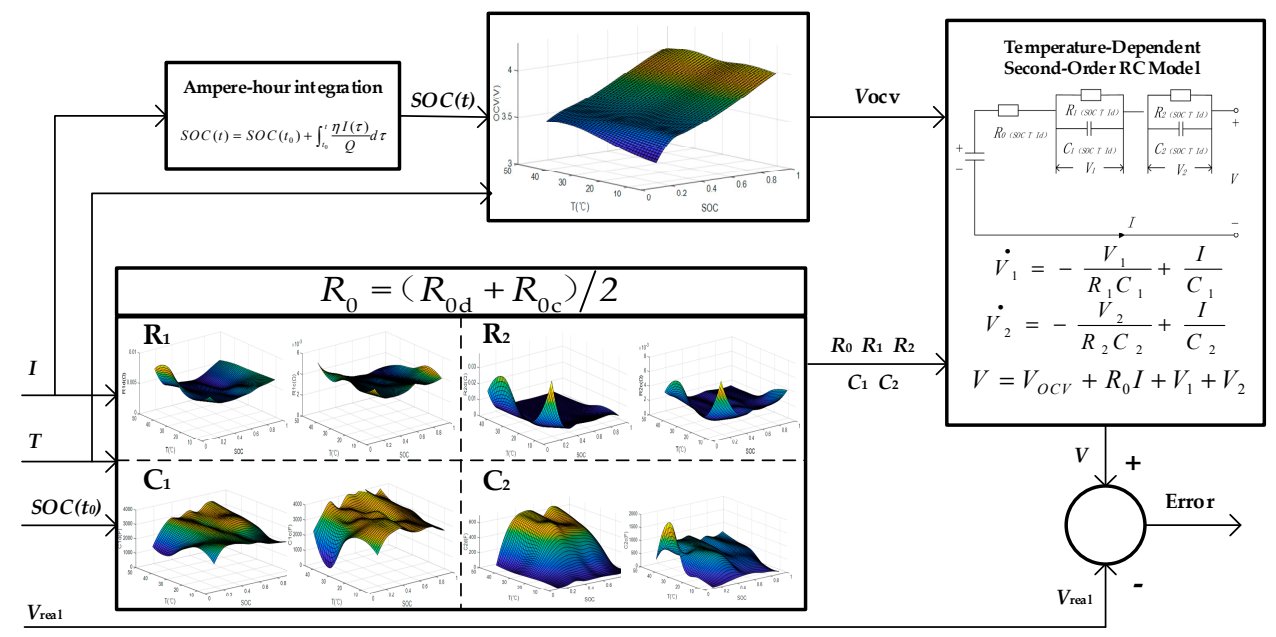

Figure 8. Schematic of the simulation model.

For verification purposes, the model has undergone the discharging test, charging test, and dynamic stress test (DST) [34], under constant and varying temperature conditions. The voltages resulting from the model as well as the voltage errors are plotted in Figure 9, under a constant ambient temperature of $25^{\circ} \mathrm{C}$. It is shown that for both the discharging and charging tests, the model output voltages are very close to the measured terminal voltages, and the voltage errors are maintained within $\pm 20 \mathrm{mV}$. As for the DST, the model output voltage follows the measured voltage very well, with a slightly increased error magnitude compared with the first two cases. Note that the error is still maintained within a very small range, that is, $\pm 50 \mathrm{mV}$.
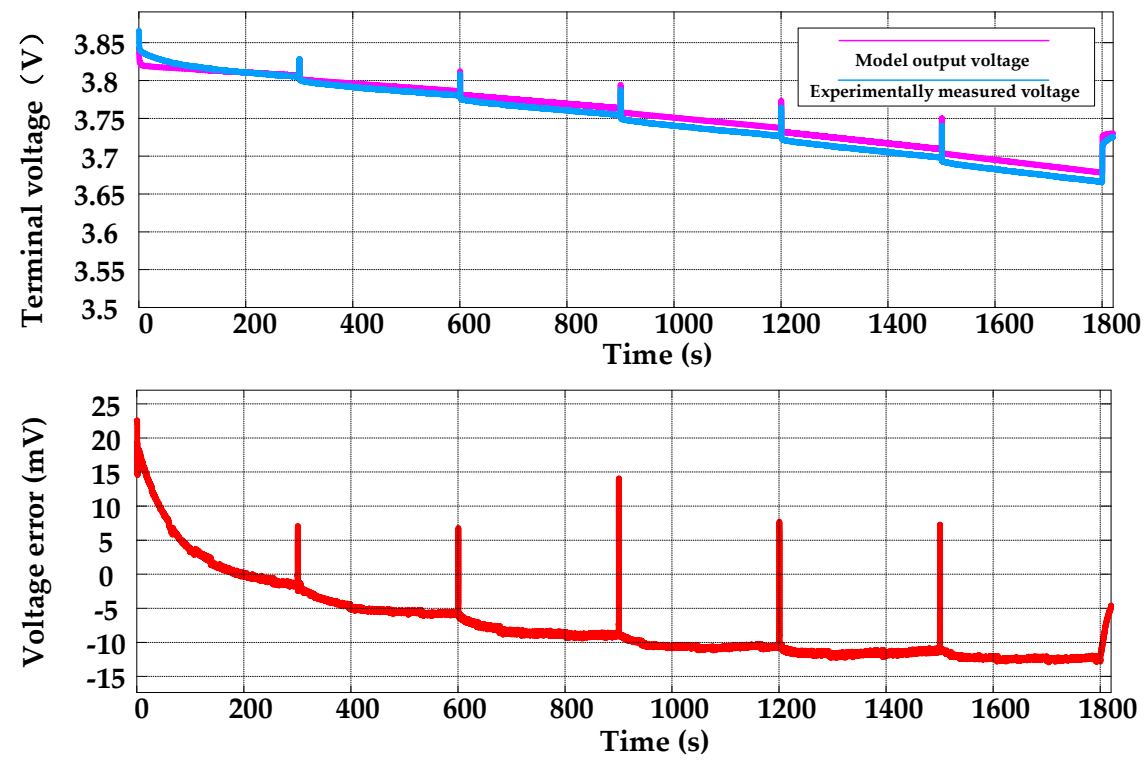

(a)

Figure 9. Cont. 

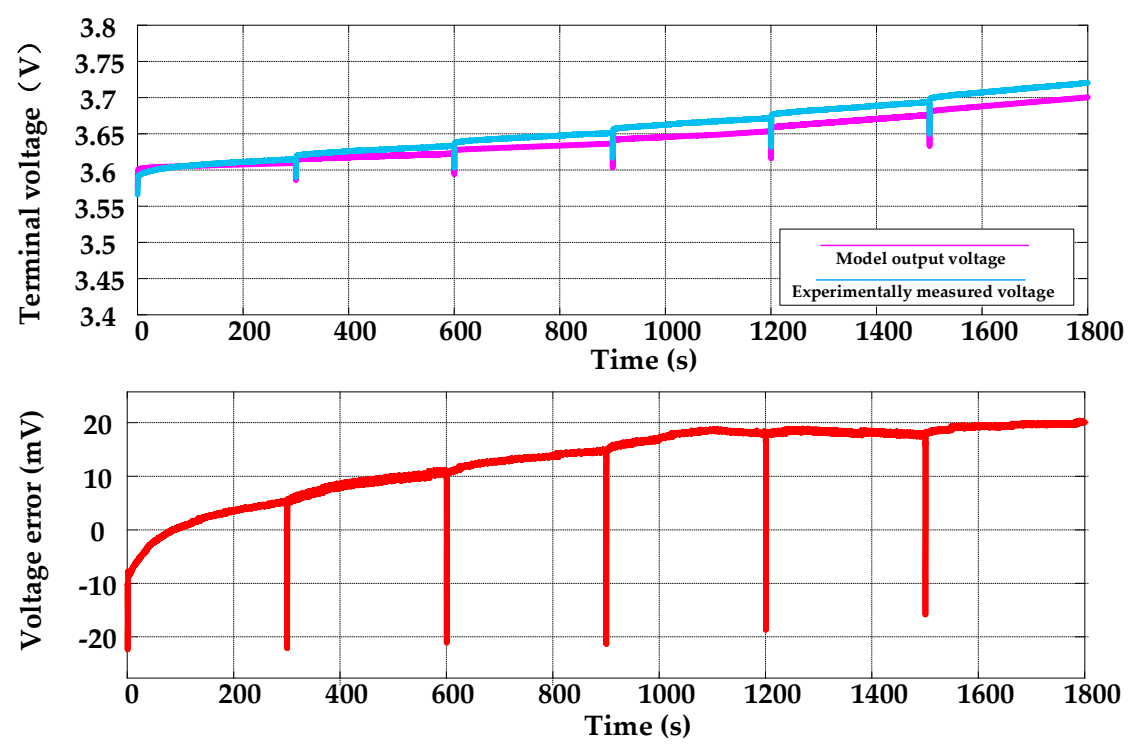

(b)
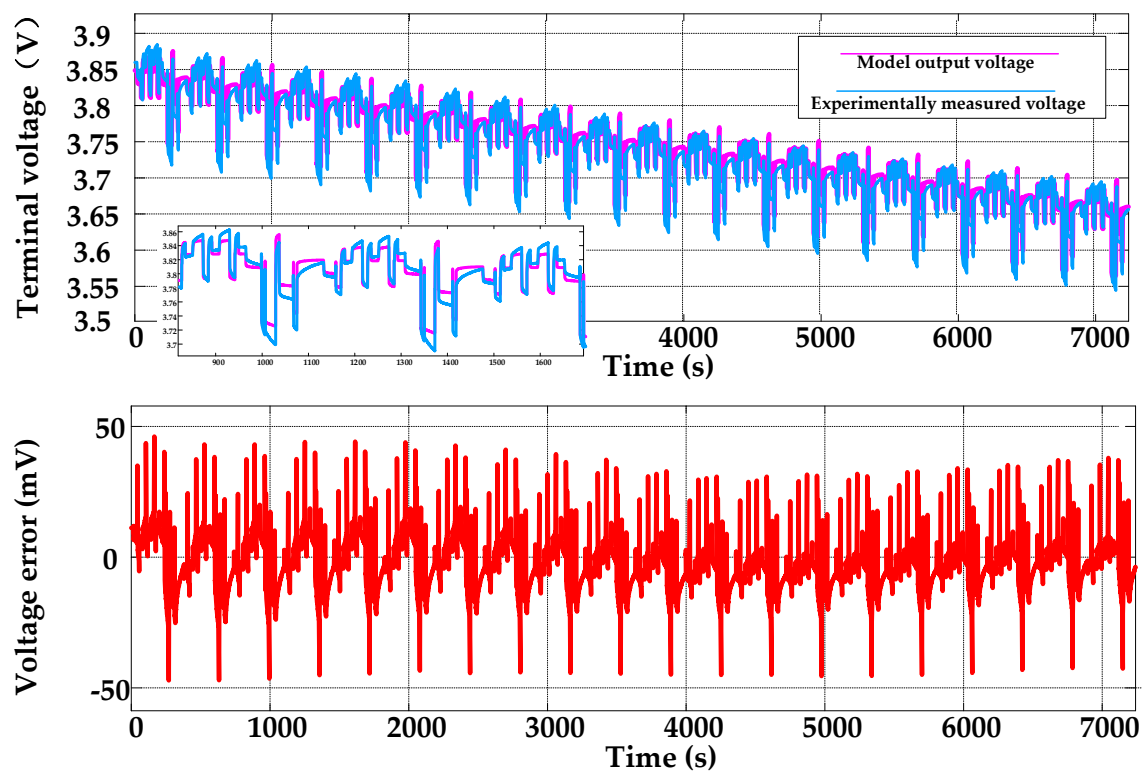

(c)

Figure 9. Model verification results at $25^{\circ} \mathrm{C}$ : (a) model output voltage and its error for the discharging test, (b) model output voltage and its error for the charging test, and (c) model output voltage and its error for the dynamic stress test (DST). The magnified mini-plot is an enlarged view for the time range of $800 \mathrm{~s}-1800 \mathrm{~s}$.

The verification results under varying temperature conditions are shown in Figure 10. In the discharging test, the ambient temperature was gradually increased from $12{ }^{\circ} \mathrm{C}$ to $20^{\circ} \mathrm{C}$. We see from Figure 10a that the model output voltage is quite close to the experimentally measured battery terminal voltage, with the voltage error remaining within $\pm 15 \mathrm{mV}$. Besides, a traditional second-order RC model, which is independent of ambient temperature, is introduced for comparison purposes, and its output voltage is represented by an orange curve. It is clearly shown that the purple curve, generated by the proposed temperature-dependent second-order RC model, is closer to the measured voltage compared with the orange curve. 
In the charging test, the ambient temperature gradually was decreased from $22{ }^{\circ} \mathrm{C}$ to $14{ }^{\circ} \mathrm{C}$. As shown in Figure 10b, similar to the previous case, the model output voltage is close to the measured voltage and the voltage error is maintained within $\pm 30 \mathrm{mV}$. Again, the purple curve, representing the proposed model, is closer to the measured voltage compared with the orange curve.

As for the DST, the ambient temperature was gradually increased from $25{ }^{\circ} \mathrm{C}$ to $40{ }^{\circ} \mathrm{C}$. In this case, the model output voltage is still close to the measured battery terminal voltage, and the voltage error is kept within $\pm 50 \mathrm{mV}$. Same as the above two cases, the proposed model outperforms traditional second-order RC model, as clearly demonstrated by the enlarged curves in Figure 10c.

The above results indicate that the established temperature-dependent second-order RC model provides not only accurate output voltage, but also good robustness against temperature variations. This verifies the superiority of the proposed model to the traditional second-order RC model under varying ambient temperature conditions.
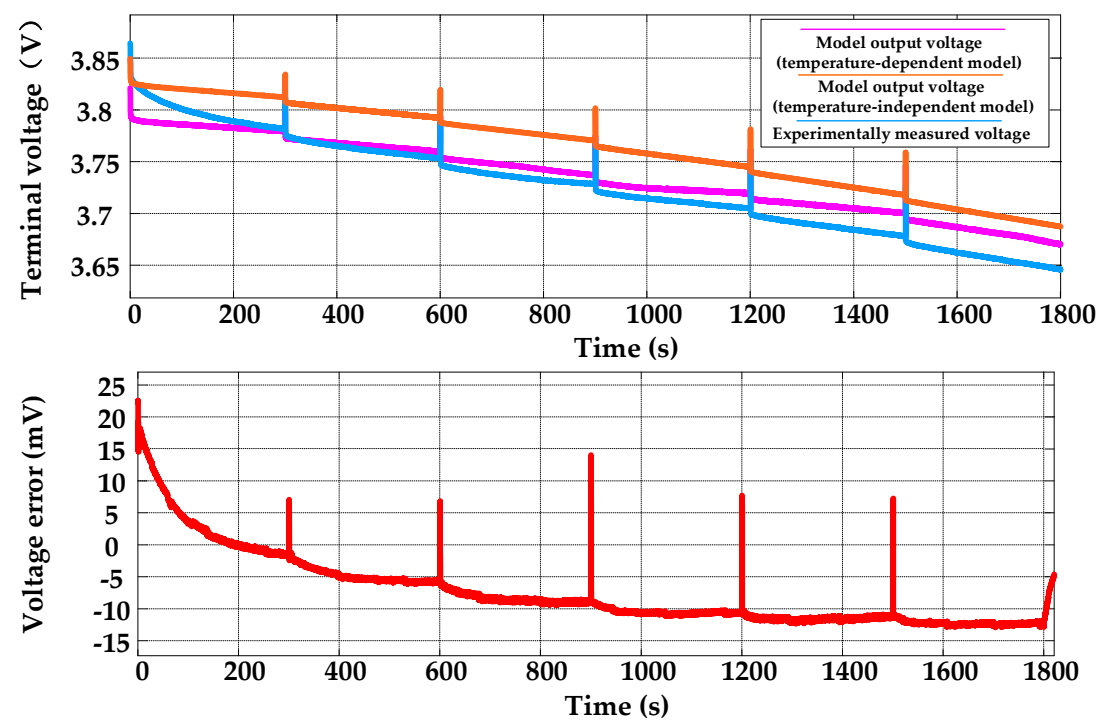

(a)
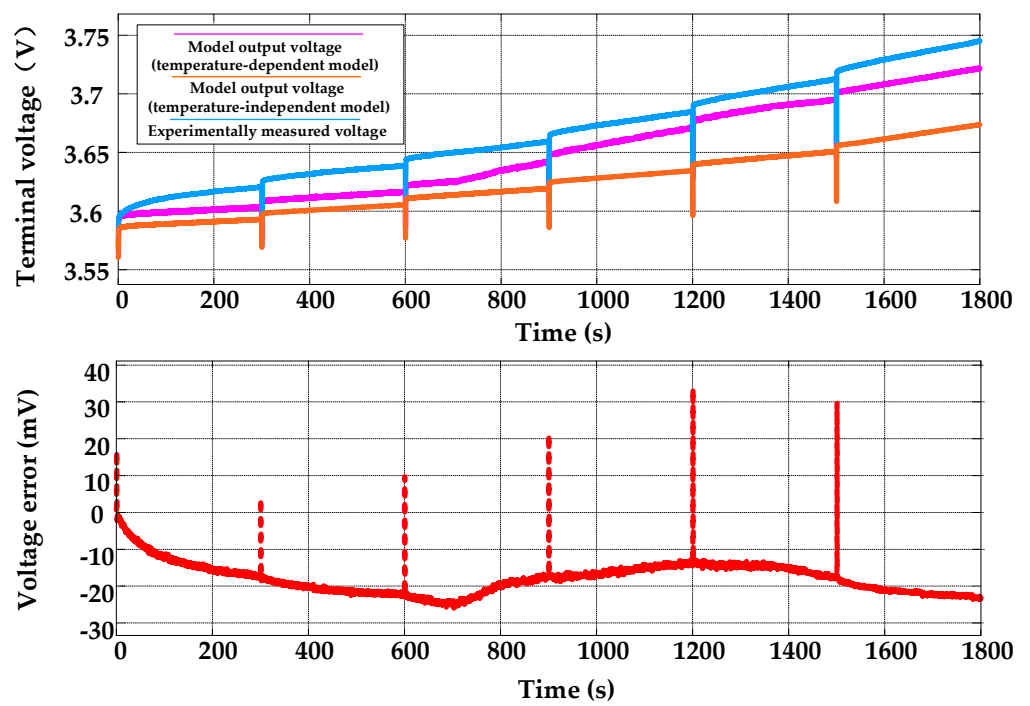

(b)

Figure 10. Cont. 

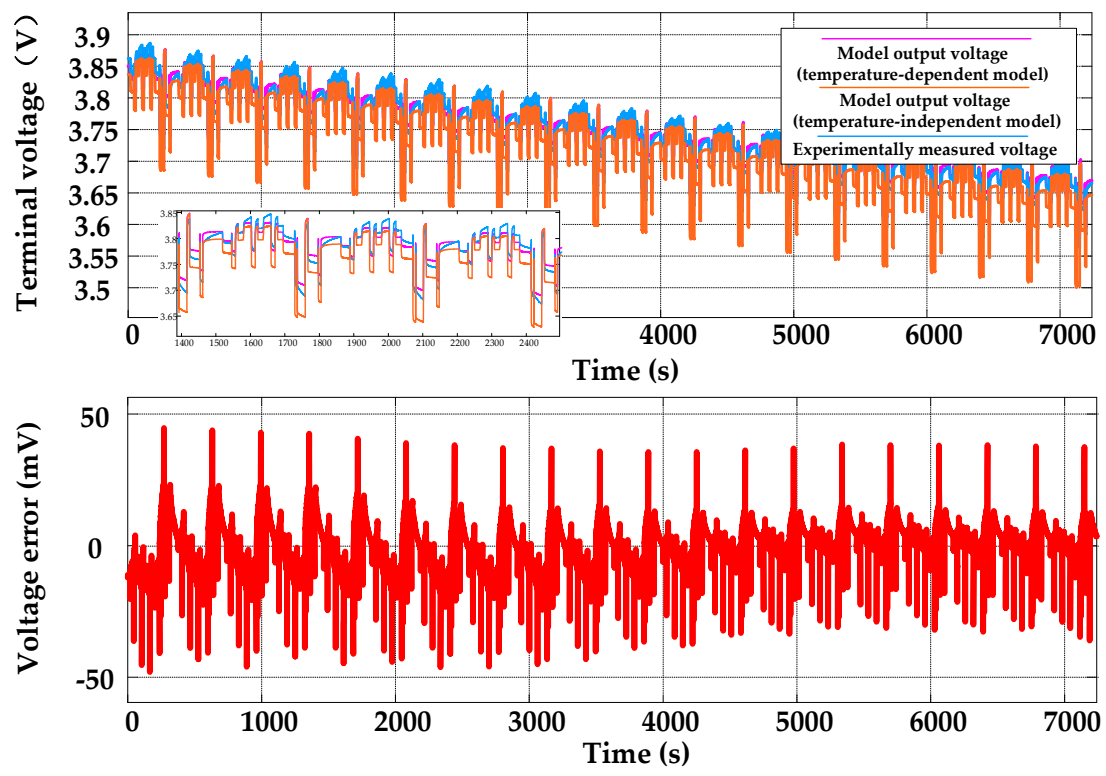

(c)

Figure 10. Model verification results under varying temperature conditions: (a) model output voltage and its error for the discharging test, (b) model output voltage and its error for the charging test, and (c) model output voltage and its error for the DST. The magnified mini-plot is an enlarged view for the time range of $1400 \mathrm{~s}-2400 \mathrm{~s}$.

\section{SOC Estimation Based on Double Kalman Filter Algorithm}

It is known that high-precision SOC estimation is crucial for batteries' safety, power characteristics, and service life, and the accuracy of SOC estimation is directly dependent on the performance of the battery model used. In this section, a double Kalman filter (DKF) algorithm is proposed for SOC estimation, based on the established temperature-dependent second-order RC model. This algorithm combines the advantages of the Ah integration method, the KF algorithm, and the EKF algorithm, and its effectiveness is verified through comparisons with the EKF algorithm.

\subsection{DKF Algorithm}

The schematic that demonstrates the structure of the proposed DKF algorithm is shown in Figure 11. This algorithm employs a two-layer filtering layout to provide SOC estimation. In the first layer, the error between the measured terminal voltage (i.e., $\left.V_{\text {real }}\right)$ and that resulting from the proposed battery model (namely $V$ ) is employed as the input to an EKF. The output from the EKF is fed to the proposed battery model to produce a corrected SOC estimate, $S O C_{\mathrm{EKF}}$. The purpose of this EKF is to deal with the uncertainties caused by modeling imperfections, thereby improving the SOC estimation performance. In the second layer, the error between $S O C_{\mathrm{EKF}}$ and that produced by the Ah integration method (denoted by $S O C_{\mathrm{Ah}}$ ) is sent to a $\mathrm{KF}$, and the output from this $\mathrm{KF}$ is then fed back to the Ah integration algorithm, which generates a further corrected SOC estimate, that is, the output SOC. The purpose of this KF is to suppress the cumulative error resulting from the Ah integration method, which further enhances the SOC estimation accuracy. 


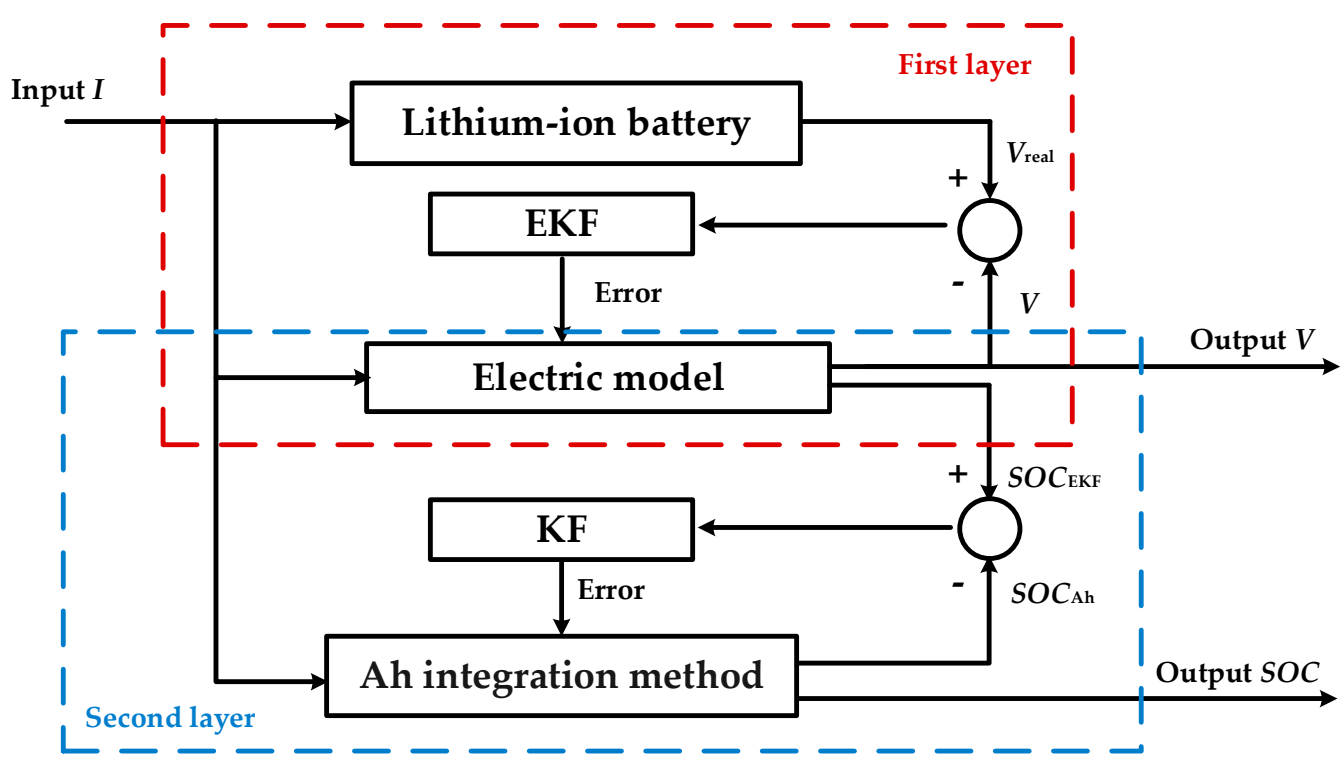

Figure 11. Schematic of the proposed dual Kalman filter (DKF) algorithm for SOC estimation. EKF, extended Kalman filter.

To implement the DKF algorithm, we first rewrite the proposed temperature-dependent second-order RC model in a discrete state space form. In this expression, the state vector is $x=$ [SOC $\left.V_{1} V_{2}\right]^{\mathrm{T}}$, the input is $u=I$ (battery current), and the output is $y=V$ (battery terminal voltage). At time $k$, this state space equation takes the following form:

$$
\left\{\begin{array}{l}
x_{\mathrm{k}+1}=A x_{\mathrm{k}}+B u_{\mathrm{k}}+\omega_{\mathrm{k}} \\
y_{\mathrm{k}}=C x_{\mathrm{k}}+D u_{\mathrm{k}}+v_{\mathrm{k}}
\end{array}\right.
$$

where $\omega_{\mathrm{k}}$ denotes the process noise; $v_{\mathrm{k}}$ represents the measurement noise; and matrices $A, B, C$, and $D$ are given by the following:

$$
\begin{gathered}
A=\left[\begin{array}{ccc}
1 & 0 & 0 \\
0 & \exp \left(\frac{-t}{R_{1} C_{1}}\right) & 0 \\
0 & 0 & \exp \left(\frac{-t}{R_{1} C_{1}}\right)
\end{array}\right], \\
B=\left[\begin{array}{c}
\frac{\eta t}{Q} \\
R_{1}\left(1-\exp \left(\frac{-t}{R_{1} C_{1}}\right)\right) \\
R_{2}\left(1-\exp \left(\frac{-t}{R_{2} C_{2}}\right)\right)
\end{array}\right], \\
C=\left[\begin{array}{ccc}
\frac{d O C V}{d S O C} & 1 & 1
\end{array}\right], \\
D=R_{0} .
\end{gathered}
$$

The detailed implementation process of the proposed DKF algorithm is as follows:

Step 1. Determination of the initial SOC value: Obtain the initial SOC value by means of the SOC-T-OCV map.

Step 2. State initialization: Determine the SOC error covariance, the process noise variance, and the measurement noise variance.

Step 3. First layer filtering: Conduct EKF-based filtering using Equations (18)-(21), and produce a corrected SOC estimate, $S O C_{\mathrm{EKF}}$.

Step 4. Second layer filtering: Conduct KF-based filtering using Equations (18)-(21), and produce a further corrected SOC estimate, that is, the output SOC.

Step 5. Iteration: Repeat steps 3 and 4 to provide real-time SOC estimation. 
Following the above recursive filtering steps, the uncertainties caused by modeling imperfections, as well as the cumulative error resulting from the Ah integration method, can both be suppressed. Through the proposed two-layer filtering mechanism, the overall SOC estimation performance is greatly improved, as we will show in the following section.

\subsection{Algorithm Verification and Discussion}

The effectiveness of the proposed DKF algorithm is verified by means of the DST. Similar to Section 4 , the SOC estimation accuracy is evaluated under both constant and varying temperature conditions. Figure 12 shows the SOC estimation results produced by the proposed DKF algorithm and the traditional EKF algorithm. We see that for both temperature conditions, the black curve (representing the DKF) is closer to the real value, with significantly fewer pulses and ripples, compared with the blue curve produced by the EKF. Besides, it is also shown in this figure that the SOC estimation errors resulting from the proposed DKF are maintained within a very small range, $\pm 0.4 \%$, for both temperature conditions. The accuracy of the EKF and the proposed DKF under different working conditions is shown in Table 5.

Note that the proposed DKF algorithm is robust to the initial SOC error. In other words, the proposed DKF is able to ensure the convergence of the estimated SOC to the real value, even if an error exists in the initial SOC value. We see that in Figure 13a, the initial SOC value fed to the DKF is higher than the real value, while in Figure 13b, the initial SOC value is lower than the real one. In both cases, the proposed DKF algorithm gradually drives the estimated SOC towards the real values, and the estimation errors are kept within $\pm 0.5 \%$ after convergence.
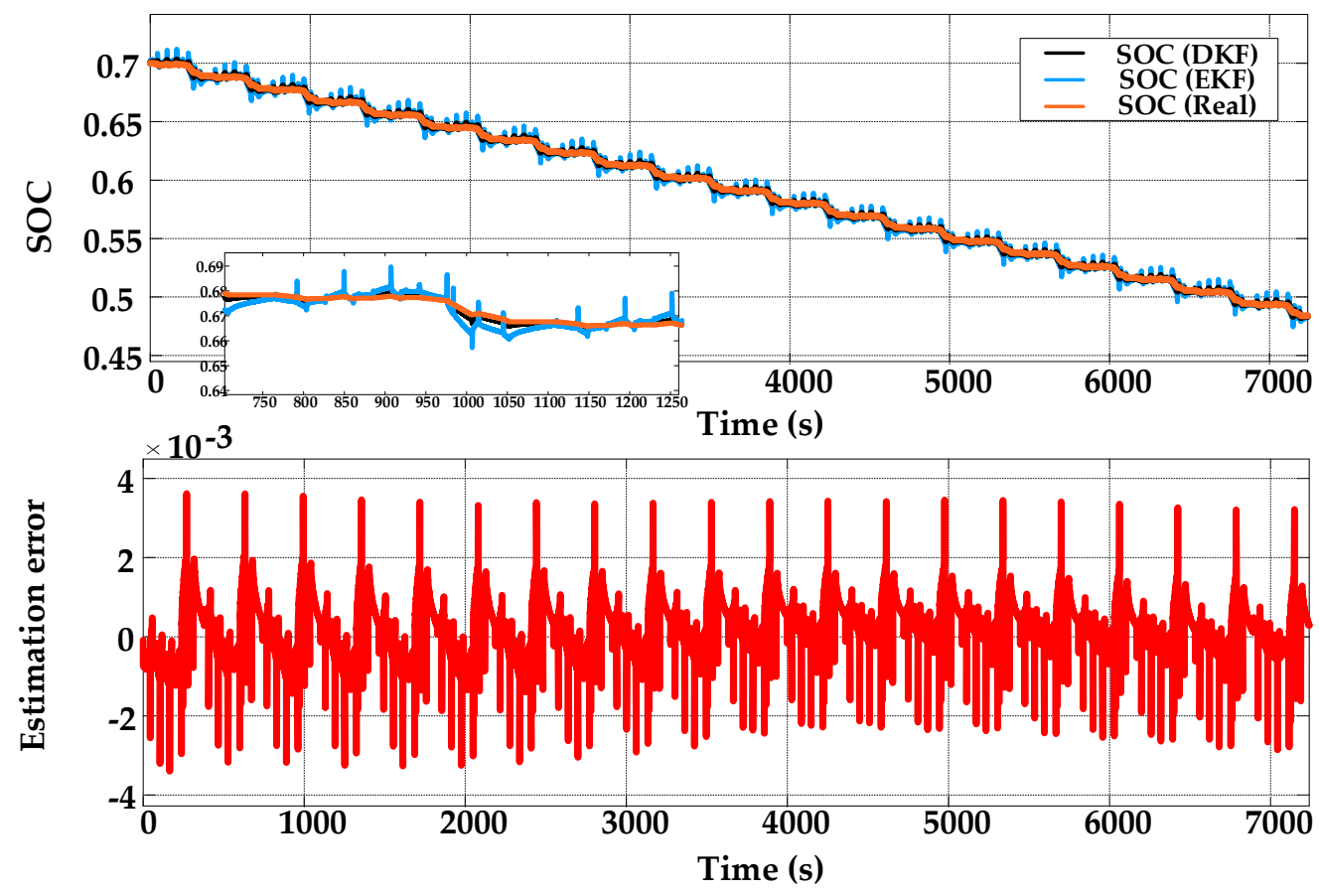

(a)

Figure 12. Cont. 

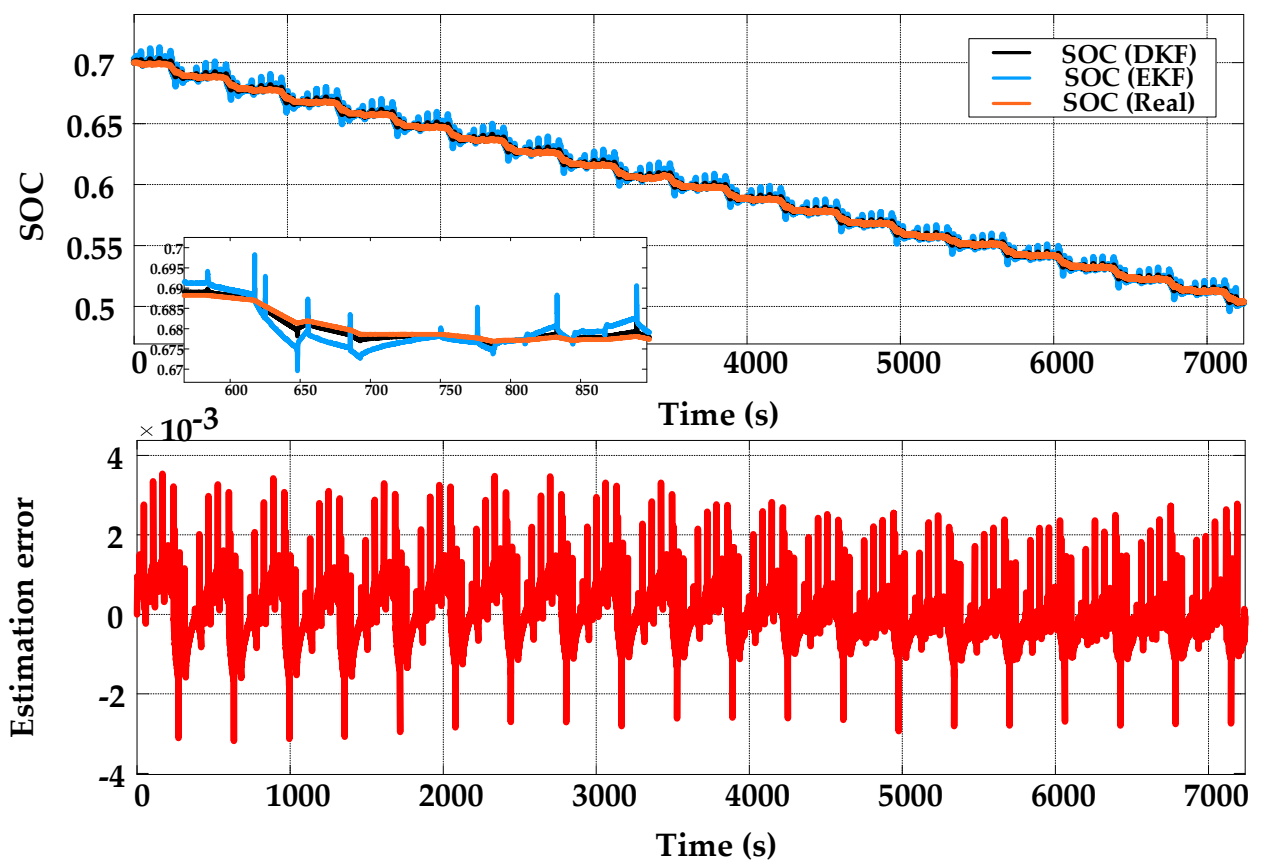

(b)

Figure 12. Algorithm verification results for the DST: (a) estimated SOC values and estimation error under constant temperature condition, the magnified mini-plot is an enlarged view for the time range of $550 \mathrm{~s}-900 \mathrm{~s}$; and (b) estimated SOC values and estimation error under varying temperature condition. The magnified mini-plot is an enlarged view for the time range of $550 \mathrm{~s}-900 \mathrm{~s}$.

Table 5. Accuracy comparison between extended Kalman filter (EKF) and dual Kalman filter (DKF) under different working conditions.

\begin{tabular}{|c|c|c|c|c|c|c|}
\hline $\begin{array}{l}\text { Working } \\
\text { Conditions }\end{array}$ & & EKF & & & DKF & \\
\hline $\begin{array}{l}\text { Constant } \\
\text { temperature }\end{array}$ & $\begin{array}{c}R^{2} \\
0.9978\end{array}$ & $\begin{array}{c}\text { Maximum } \\
\text { error } \\
0.0134\end{array}$ & $\begin{array}{c}\text { Average } \\
\text { error } \\
0.0024\end{array}$ & $\begin{array}{c}\mathrm{R}^{2} \\
0.9998\end{array}$ & $\begin{array}{c}\text { Maximum } \\
\text { error } \\
0.0036\end{array}$ & $\begin{array}{c}\text { Average } \\
\text { error } \\
0.0006\end{array}$ \\
\hline $\begin{array}{c}\text { Varying } \\
\text { temperature }\end{array}$ & $\begin{array}{c}R^{2} \\
0.9984\end{array}$ & $\begin{array}{l}\text { Maximum } \\
\text { error } \\
0.131\end{array}$ & $\begin{array}{c}\text { Average } \\
\text { error } \\
0.0018\end{array}$ & $\begin{array}{c}\mathrm{R}^{2} \\
0.9999\end{array}$ & $\begin{array}{c}\text { Maximum } \\
\text { error } \\
0.0035\end{array}$ & $\begin{array}{c}\text { Average } \\
\text { error } \\
0.0005\end{array}$ \\
\hline
\end{tabular}

The above verification results indicate that the proposed DKF algorithm, constructed based on the established temperature-dependent second-order RC model, outperforms the traditional and classical EKF algorithm in terms of SOC estimation, under both constant and varying temperature conditions. In addition, the proposed DKF provides good robustness against initial SOC errors, which guarantees the performance of the DKF even if the initial SOC cannot be accurately obtained. 

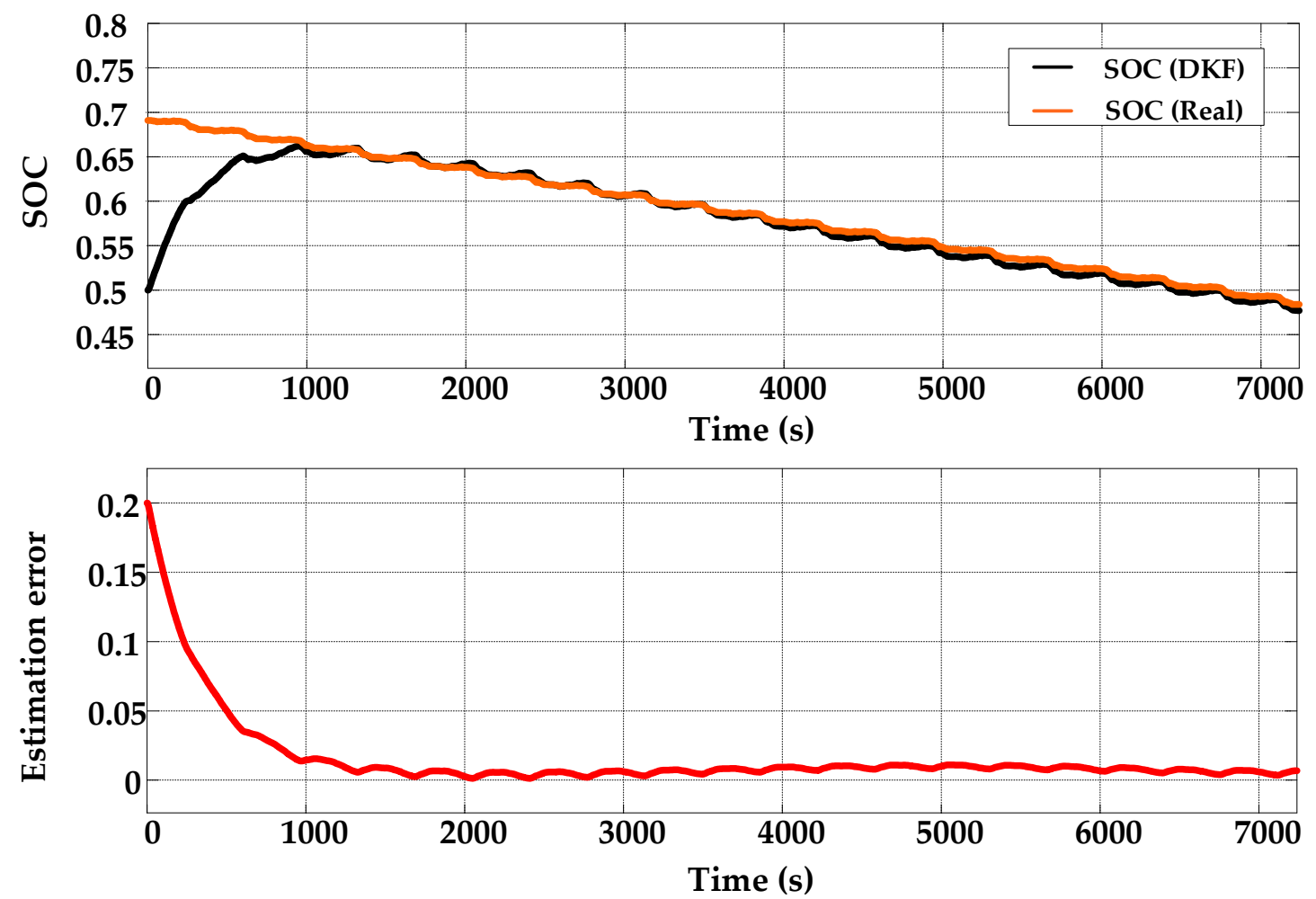

(a)
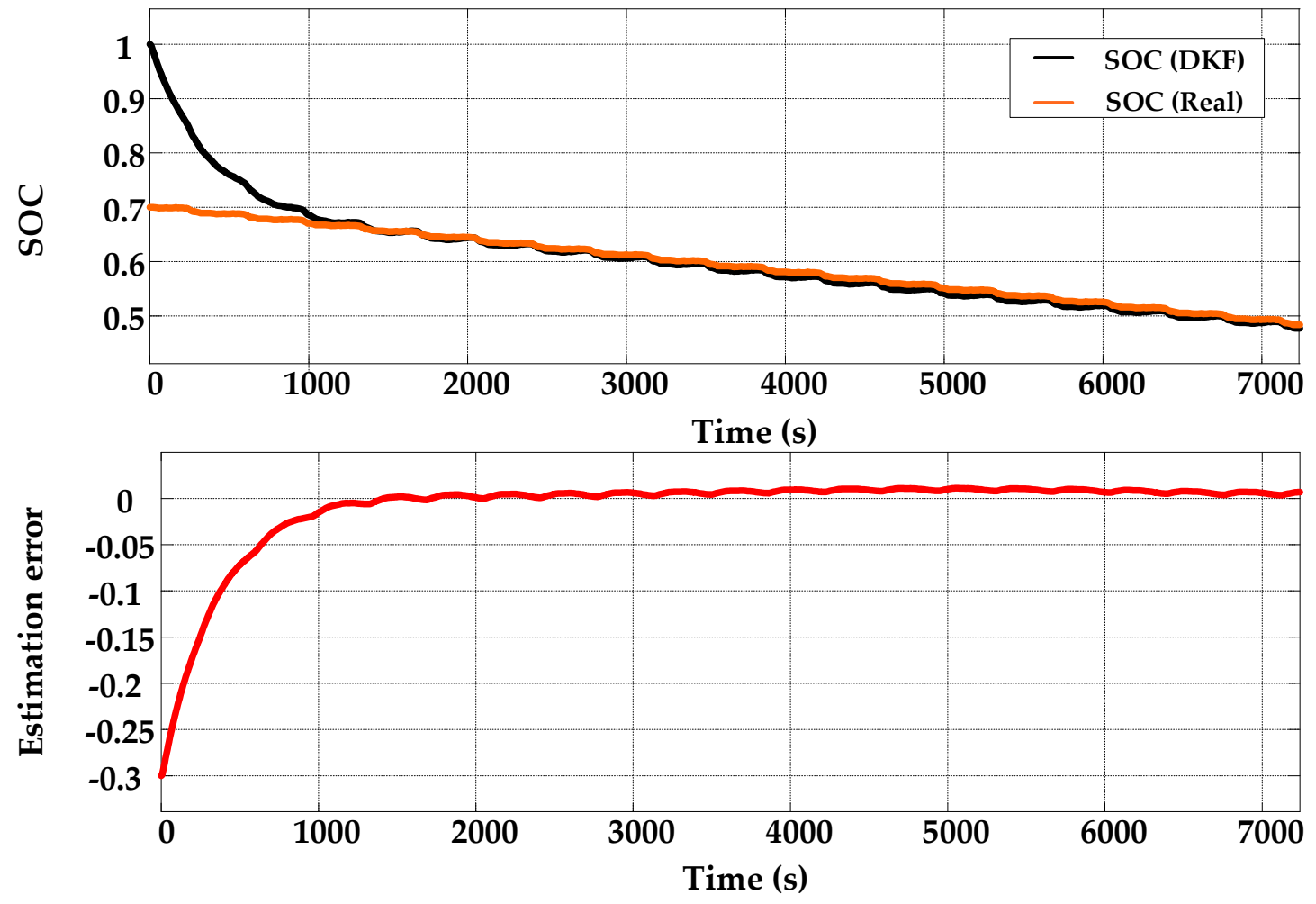

(b)

Figure 13. Algorithm verification results with initial SOC errors: (a) estimated SOC and corresponding estimation error with an initial SOC value of $0.5,(\mathbf{b})$ estimated SOC and corresponding estimation error with an initial SOC value of 1. 


\section{Conclusions}

The battery electrical characteristics are dependent on the ambient temperature; however, most existing battery equivalent circuit models have not taken into account the influences of ambient temperature. In this paper, a temperature-dependent second-order RC equivalent circuit model is established, based on the electrical characteristics of lithium-ion batteries at different ambient temperatures $\left(5^{\circ} \mathrm{C}, 15^{\circ} \mathrm{C}, 25^{\circ} \mathrm{C}, 35^{\circ} \mathrm{C}\right.$, and $\left.45^{\circ} \mathrm{C}\right)$. The unknown model parameters are identified by means of experiments, and the accuracy of the proposed battery model is verified under constant and varying temperature conditions. It is shown that for both the discharging and charging tests, the model errors are maintained within $\pm 30 \mathrm{mV}$. As for the DST, the accuracy of the model is reduced, but the error is still maintained within a very small range, that is, $\pm 50 \mathrm{mV}$. These verification results indicate that the proposed model provides not only accurate output voltage, but also good robustness against temperature variations. Besides, it is also shown that the proposed model outperforms the traditional second-order RC model under varying ambient temperature conditions.

On the basis of the proposed temperature-dependent second-order RC model, a DKF algorithm that combines the Ah integration method, the KF algorithm, and the EKF algorithm is proposed for SOC estimation. This algorithm employs a two-layer filtering mechanism to enhance SOC estimation performance, which suppresses the uncertainties caused by modeling imperfections, as well as the cumulative error resulting from the Ah integration method. The effectiveness of the proposed DKF algorithm is verified by means of the DST, under both constant and varying temperature conditions. The verification results indicate that the proposed DKF algorithm outperforms the traditional and classical EKF algorithm, with the SOC estimation errors under different temperature conditions maintained within $\pm 0.4 \%$. Besides, it is also proven that the proposed DKF algorithm provides good robustness against temperature variations and initial SOC errors.

Lithium-ion batteries will age with the increase of the number of cycles. Consequently, the parameters of the battery model will also change with time. In our future work, the battery lifetime experiments will be performed to obtain battery aging data, based on which a more advanced battery model considering battery aging will be investigated and utilized for better battery state estimation.

Author Contributions: Conceptualization, M.H.; methodology, M.H.; validation, Z.S.; formal analysis, Y.X.; investigation, Y.X., K.C., Z.S. and Z.Y.; writing—original draft preparation, Y.X.; writing-review and editing, C.F.; supervision, M.H. and C.F.; project administration, K.C. and Z.Y.; funding acquisition, M.H. and C.F.

Funding: This research was funded by the National Key Research and Development Project, grant number 2018 YFB0106102.

Conflicts of Interest: The authors declare no conflict of interest. The funders had no role in the design of the study; in the collection, analyses, or interpretation of data; in the writing of the manuscript; or in the decision to publish the results.

\section{References}

1. Chaoui, H.; Ibe-Ekeocha, C.C. State of Charge and State of Health Estimation for Lithium Batteries Using Recurrent Neural Networks. IEEE Trans. Veh. Technol. 2017, 66, 8773-8783. [CrossRef]

2. Ng, K.S.; Moo, C.S.; Chen, Y.P.; Hsieh, Y.C. Enhanced coulomb counting method for estimating state-of-charge and state-of-health of lithium-ion batteries. Appl. Energy 2009, 86, 1506-1511. [CrossRef]

3. Stan, A.I.; Swierczynski, M.; Stroe, D.I.; Teodorescu, R.; Andreasen, S.J. Lithium Ion Battery Chemistries from Renewable Energy Storage to Automotive and Back-up Power Applications-An Overview. In Proceedings of the 2014 International Conference on Optimization of Electrical and Electronic Equipment (Optim), Bran, Romania, 22-24 May 2014; pp. 713-720.

4. Xiong, R.; Cao, J.Y.; Yu, Q.Q.; He, H.W.; Sun, F.C. Critical Review on the Battery State of Charge Estimation Methods for Electric Vehicles. IEEE Access 2018, 6, 1832-1843. [CrossRef]

5. Yang, N.X.; Zhang, X.W.; Shang, B.B.; Li, G.J. Unbalanced discharging and aging due to temperature differences among the cells in a lithium-ion battery pack with parallel combination. J. Power Sources 2016, 306, 733-741. [CrossRef] 
6. Deng, Y.; Hu, Y.L.; Cao, Y. An Improved Algorithm of SOC Testing Based on Open-Circuit Voltage-Ampere Hour Method. Intell. Comput. Smart Grid Electr. Veh. 2014, 463, 258-267.

7. Lee, S.; Kim, J.; Lee, J.; Cho, B.H. State-of-charge and capacity estimation of lithium-ion battery using a new open-circuit voltage versus state-of-charge. J. Power Sources 2008, 185, 1367-1373. [CrossRef]

8. Orchard, M.E.; Hevia-Koch, P.; Zhang, B.; Tang, L. Risk Measures for Particle-Filtering-Based State-of-Charge Prognosis in Lithium-Ion Batteries. IEEE Trans. Ind. Electron. 2013, 60, 5260-5269. [CrossRef]

9. Piller, S.; Perrin, M.; Jossen, A. Methods for state-of-charge determination and their applications. J. Power Sources 2001, 96, 113-120. [CrossRef]

10. Tulsyan, A.; Tsai, Y.; Gopaluni, R.B.; Braatz, R.D. State-of-charge estimation in lithium-ion batteries: A particle filter approach. J. Power Sources 2016, 331, 208-223. [CrossRef]

11. Plett, G.L. Extended Kalman filtering for battery management systems of LiPB-based HEV battery packs. Part 3. State and parameter estimation. J. Power Sources 2004, 134, 277-292. [CrossRef]

12. Plett, G.L. Sigma-point Kalman filtering for battery management systems of LiPB-based HEV battery packs-Part 2: Simultaneous state and parameter estimation. J. Power Sources 2006, 161, 1369-1384. [CrossRef]

13. Sun, F.C.; Xiong, R.; He, H.W. A systematic state-of-charge estimation framework for multi-cell battery pack in electric vehicles using bias correction technique. Appl. Energy 2016, 162, 1399-1409. [CrossRef]

14. Waag, W.; Fleischer, C.; Sauer, D.U. Critical review of the methods for monitoring of lithium-ion batteries in electric and hybrid vehicles. J. Power Sources 2014, 258, 321-339. [CrossRef]

15. Zheng, Y.J.; Ouyang, M.G.; Han, X.B.; Lu, L.G.; Li, J.Q. Investigating the error sources of the online state of charge estimation methods for lithium-ion batteries in electric vehicles. J. Power Sources 2018, 377, 161-188. [CrossRef]

16. Cai, C.H.; Du, D.; Liu, Z.Y.; Zhang, H. Artificial neural network in estimation of battery state-of-charge (SOC) with nonconventional input variables selected by correlation analysis. In Proceedings of the 2002 International Conference on Machine Learning and Cybernetics, Beijing, China, 4-5 November 2002; Volume 3, pp. 1619-1625.

17. He, H.W.; Zhang, X.W.; Xiong, R.; Xu, Y.L.; Guo, H.Q. Online model-based estimation of state-of-charge and open-circuit voltage of lithium-ion batteries in electric vehicles. Energy 2012, 39, 310-318. [CrossRef]

18. Shi, Q.-S.; Zhang, C.-H.; Cui, N.-X. Estimation of battery state-of-charge using $v$-support vector regression algorithm. Int. J. Automot. Technol. 2008, 9, 759-764. [CrossRef]

19. Schwunk, S.; Armbruster, N.; Straub, S.; Kehl, J.; Vetter, M. Particle filter for state of charge and state of health estimation for lithium-iron phosphate batteries. J. Power Sources 2013, 239, 705-710. [CrossRef]

20. Khumprom, P.; Yodo, N. A data-driven predictive prognostic model for lithium-ion batteries based on a deep learning algorithm. Energies 2019, 12, 660. [CrossRef]

21. Li, C.; Xiao, F.; Fan, Y. An approach to state of charge estimation of lithium-ion batteries based on recurrent neural networks with gated recurrent unit. Energies 2019, 12, 1592. [CrossRef]

22. Zenati, A.; Desprez, P.; Razik, H. Estimation of the SOC and the SOH of Li-ion Batteries, by combining Impedance Measurements with the Fuzzy Logic Inference. In Proceedings of the 36th Annual Conference on IEEE Industrial Electronics Society (IECON 2010), Glendale, AZ, USA, 7-10 November 2010; pp. 1773-1778.

23. Bhangu, B.S.; Bentley, P.; Stone, D.A.; Bingham, C.M. Nonlinear Observers for Predicting State-of-Charge and State-of-Health of Lead-Acid Batteries for Hybrid-Electric Vehicles. IEEE Trans. Veh. Technol. 2005, 54, 783-794. [CrossRef]

24. Chen, Z.; Fu, Y.H.; Mi, C.C. State of Charge Estimation of Lithium-Ion Batteries in Electric Drive Vehicles Using Extended Kalman Filtering. IEEE Trans. Veh. Technol. 2013, 62, 1020-1030. [CrossRef]

25. Li, S.X.; Hu, M.H.; Li, Y.X.; Gong, C.C. Fractional-order modeling and SOC estimation of lithium-ion battery considering capacity loss. Int. J. Energy Res. 2019, 43, 417-429. [CrossRef]

26. Duong, V.H.; Bastawrous, H.A.; Lim, K.; See, K.W.; Zhang, P.; Dou, S.X. Online state of charge and model parameters estimation of the $\mathrm{LiFePO} 4$ battery in electric vehicles using multiple adaptive forgetting factors recursive least-squares. J. Power Sources 2015, 296, 215-224. [CrossRef]

27. Yang, F.F.; Xing, Y.J.; Wang, D.; Tsui, K.L. A comparative study of three model-based algorithms for estimating state-of-charge of lithium-ion batteries under a new combined dynamic loading profile. Appl. Energy 2016, 164, 387-399. [CrossRef] 
28. Rooij, D.M.R.D. Electrochemical Methods: Fundamentals and Applications. Anti Corros. Methods Mater. 2003, 50, 414-421. [CrossRef]

29. Yatsui, M.W.; Bai, H. Kalman filter based state-of-charge estimation for lithium-ion batteries in hybrid electric vehicles using pulse charging. In Proceedings of the 2011 IEEE Vehicle Power and Propulsion Conference, Chicago, IL, USA, 6-9 September 2011.

30. Hu, M.H.; Li, Y.X.; Li, S.X.; Fu, C.Y.; Qin, D.T.; Li, Z.H. Lithium-ion battery modeling and parameter identification based on fractional theory. Energy 2018, 165, 153-163. [CrossRef]

31. Idaho National Engineering and Environmental Laboratory. FreedomCAR Battery Test Manual for Power-Assist Hybrid Electric Vehicles; INEEL (DOE/ID-11069): Cuernavaca, Mexico, 2003.

32. Zhu, Q.; Xiong, N.; Yang, M.L.; Huang, R.S.; Hu, G.D. State of Charge Estimation for Lithium-Ion Battery Based on Nonlinear Observer: An H-infinity Method. Energies 2017, 10, 679. [CrossRef]

33. Zhu, Q.; Li, L.; Hu, X.S.; Xiong, N.; Hu, G.D. H-infinity-Based Nonlinear Observer Design for State of Charge Estimation of Lithium-Ion Battery with Polynomial Parameters. IEEE Trans. Veh. Technol. 2017, 66, 10853-10865. [CrossRef]

34. Idaho National Engineering Laboratory. USABC Electric Vehicle Battery Test Procedures Manual-Revision 2; INEEL (DOE/ID-10479): Cuernavaca, Mexico, 1996.

(C) 2019 by the authors. Licensee MDPI, Basel, Switzerland. This article is an open access article distributed under the terms and conditions of the Creative Commons Attribution (CC BY) license (http://creativecommons.org/licenses/by/4.0/). 